\title{
Three-Phase Asymmetrical Induction Motor Fed by a Single-Phase Distribution System - Detailed Mathematical Model
}

\author{
R.G. de Mendonça, MSc; L. Martins Neto, Dr; J.R. Camacho, PhD. \\ UFU/ DEENE/ LabMaq \\ P.O.Box: 593 - Campus Santa Mônica \\ CEP: 38400-902 - Uberlândia - MG - Brazil \\ jrcamacho@ufu.br
}

\begin{abstract}
This paper focuses a time domain model, a three-phase asymmetrical induction motor fed by a single-phase distribution system. A low cost solution for a common problem in Brazilian rural areas. The main effort in this case is to obtain a feedback on the design of asymmetrical three-phase induction motors with a singlephase feeding who intend to be a low cost and useful option for rural applications. Modeling was validated by the design and construction of a $2 \mathrm{HP}$ asymmetrical three-phase induction motor, in this case theoretical analysis are compared with experimental results. This comparison will allow us to obtain conclusions on this machine global behavior under full-load operation.
\end{abstract}

Index terms - Induction Motor, Model, Asymmetry.

\section{INTRODUCTION}

Countries with extensive rural industry and land extensions where the main characteristics of electrical power consumers are a low monthly $\mathrm{kWh}$ consumption; low number of consumers per $\mathrm{km}$ of rural network; low coincidence factor. Add to that scenario the limited financial resources to be applied in rural electrification programs, for this purpose Brazil is taken as an example. In this case Electrical Utility Companies, in order to make the most with low resources available need to expand their rural network with a single-phase distribution system. It is clear then, the rural energy consumer has a urgent need for energy in his farm with the purpose of a better work environment, a profitable rural property and all the resources given by electrical apparatus. The mentioned consumer will be locked with the single-phase system peculiarities. The use of typical three-phase loads, being an example the induction motor with power above 12.5 HP. Due to its size, it has its utilization restricted to a threephase rural consumers only. The substitution in rural areas of a single-phase network by a three-phase network in many cases can be financially prohibitive. Alternatives to network upgrading could be the use of single to three-phase static or rotary converters[3], or to use a more contemporary and lower-cost alternative, the three-phase asymmetrical induction motor fed by a single-phase source[5]. Those references take in consideration a similar problem with the use of the frequency domain modeling. However, a very important question not addressed in previous publications is the time domain linear analysis, considering magnetic saturation, under dynamic operating conditions. In this case it will be possible to analyze the electromagnetic torque oscillations for the asymmetrical three-phase induction motor with single-phase feeding.

As in references [1], [6], [7], [8] and [9], the asymmetrical three-phase induction motor is developed from the symmetrical three-phase induction motor. This is made only by making different the number of turns in each stator phase. Generically speaking this motor has unbalanced magnetomotrice forces ( $\mathrm{mmf}$ ) in each phase. This unbalancing allows the decomposition of such $\mathrm{mmf}$ distributions in such a way that can be obtained the distribution of static and rotary magnetic fields, where the later ones are of positive and negative sequences. The positive sequence rotary magnetic field, $\mathrm{B}_{\mathrm{E} 1}$, according to the symmetrical induction motor operating principle, also produces indirectly a rotary magnetic field, $\mathrm{B}_{\mathrm{R} 1}$, with the same sequence of the machine rotor. The same happen with negative sequence rotary magnetic field, $\mathrm{B}_{\mathrm{E} 2}$, producing a magnetic field $B_{R 2}$, where the rotating field is opposite to the machine rotor speed. Figure 1 illustrate this affirmative.

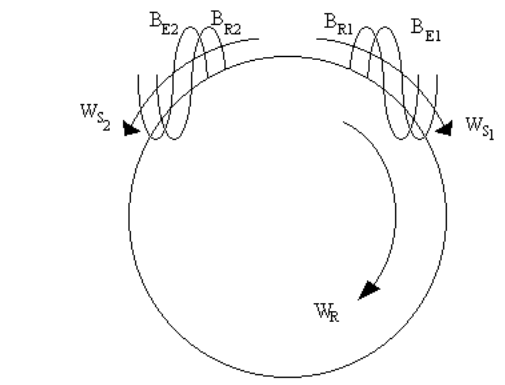

Figure 1 - Representation of rotating magnetic fields.

With the observation of Figure 1 one can reach the following conclusions in steady state:

- the two pairs of magnetic fields $\mathrm{B}_{\mathrm{E} 1}, \mathrm{~B}_{\mathrm{R} 1}$ and $\mathrm{B}_{\mathrm{E} 2}, \mathrm{~B}_{\mathrm{R} 2}$ have a constant displacement angle between them, therefore the alignment resulting electromagnetic torque is constant;

- the angular position between the two pairs of magnetic fields $\mathrm{B}_{\mathrm{E} 1}$ and $\mathrm{B}_{\mathrm{R} 2}$ and $\mathrm{B}_{\mathrm{E} 2}, \mathrm{~B}_{\mathrm{R} 1}$ is a periodical variable, therefore the resulting electromagnetic torque alignment is oscillatory.

The main proposal in this paper is the mathematical model for the asymmetrical induction motor covering mechanical and electrical transients, and also the unbalancing factor already defined in previous references. From the modeling can be defined the design philosophy 
for the asymmetrical motor. Therefore, building a prototype a comparison of theoretical and experimental results can be made and will validate the presented model.

\section{MATHEMATICAL MODEL}

For the sake of simplicity, the development of mathematical equations will be made from a generic winding consisting of two phases " $i$ " and " $j "$. In the following paragraphs this concept will be extended to the single phase fed asymmetrical machine. Machine equations can be written based in Figure 2, which shows a transverse cut of machine stator windings.

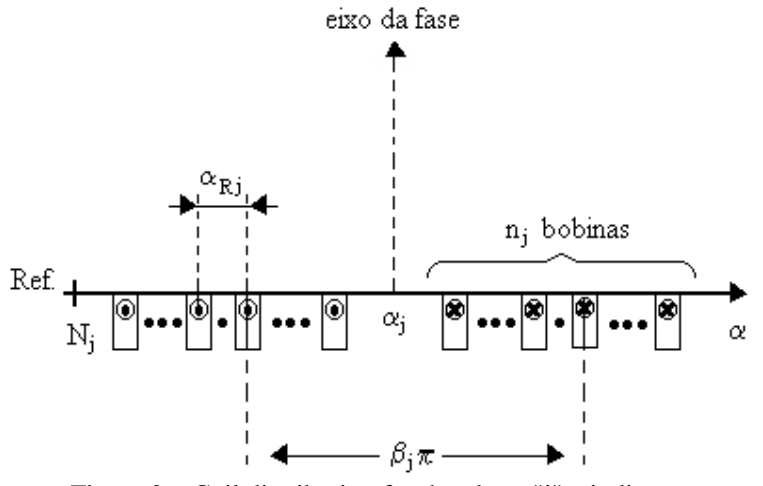

Figure 2 - Coil distribution for the phase "j" windings.

Taking in consideration two generic motor "i" e " $j$ " the following equations can be written:

$$
\begin{aligned}
& \mathrm{v}_{\mathrm{i}}=\mathrm{r}_{\mathrm{i}} \cdot \mathrm{i}_{\mathrm{i}}+\frac{\mathrm{d} \lambda_{\mathrm{i}}}{\mathrm{dt}} \\
& v_{j}=r_{j} \cdot i_{j}+\frac{d \lambda_{j}}{d t} \\
& \lambda_{\mathrm{i}}=\mathrm{L}_{\mathrm{ii}} \cdot \mathrm{i}_{\mathrm{i}}+\mathrm{L}_{\mathrm{ij}} \cdot \mathrm{i}_{\mathrm{j}}+\mathrm{L}_{\mathrm{di}} \cdot \mathrm{i}_{\mathrm{i}} \\
& \lambda_{\mathrm{j}}=\mathrm{L}_{\mathrm{j} j} \cdot \mathrm{i}_{\mathrm{j}}+\mathrm{L}_{\mathrm{ij}} \cdot \mathrm{i}_{\mathrm{i}}+\mathrm{L}_{\mathrm{dj}} \cdot \mathrm{i}_{\mathrm{j}}
\end{aligned}
$$

where:

$v_{i}, v_{j}$ - voltages at phases " $i$ " and " $j$ ";

$\mathrm{i}_{\mathrm{i}}, \mathrm{i}_{\mathrm{j}}$ - currents at phases "i" and " $\mathrm{j}$ ";

$\lambda_{i}, \lambda_{j}$ - magnetic fluxes of phases "i" and " $j$ ";

$r_{i}, r_{j}$ - resistance for phases "i" and " $j$ ";

$\mathrm{L}_{\mathrm{ii}}, \mathrm{L}_{\mathrm{jj}}$ - self inductances for phases “i” e “j”, without leakage;

$\mathrm{L}_{\mathrm{ij}}$ - mutual inductances between phases " $\mathrm{i}$ " e " $\mathrm{j}$ ", and;

$\mathrm{L}_{\mathrm{di}}, \mathrm{L}_{\mathrm{dj}}$ - leakage indutcances for phases "i $\mathrm{i}$ " and " $\mathrm{j}$ ", respectively.

The magnetomotrice force of phase " $\mathrm{j}$ " is given by:

$\operatorname{Fmm}_{\mathrm{jh}}(\alpha)=\frac{2}{\pi} \cdot \mathrm{N}_{\mathrm{j}} \cdot \mathrm{n}_{\mathrm{j}} \cdot \mathrm{k}_{\mathrm{pjh}} \cdot \mathrm{k}_{\mathrm{djh}} \cdot \mathrm{i}_{\mathrm{j}} \cdot \frac{1}{\mathrm{~h}} \cdot \cos \left[\mathrm{h} \cdot\left(\alpha-\alpha_{\mathrm{j}}\right)\right]$

where:

$\mathrm{k}_{\mathrm{pjh}}, \mathrm{k}_{\mathrm{djh}}$ - step and distribution factors, respectively, for the $h^{\text {th }}$ harmonics, given equations (6) and (7).

$$
\begin{aligned}
& \mathrm{k}_{\mathrm{pj} \mathrm{h}}=\operatorname{sen}\left(\mathrm{h} \cdot \beta_{\mathrm{j}} \cdot \frac{\pi}{2}\right) \\
& k_{d \mathrm{jh}}=\frac{\operatorname{sen}\left(h \cdot n_{j} \cdot{ }^{\alpha^{R j}}{ }^{2}\right)}{n j \cdot \operatorname{sen}\left(h \cdot{ }^{\alpha^{R j}}\right)}
\end{aligned}
$$

The magnetic field density distribution $\mathrm{B}_{\mathrm{jh}}$ produced by $\operatorname{Fmm}_{\mathrm{jh}}(\alpha)$ is obtained through the Ampere's Law and the result is given by equation (8). In this case the iron's magnetic circuit reluctance is neglected when compared with air-gap's reluctance, considered uniform.

$$
B_{j h}(\alpha)=\frac{2}{\pi} \cdot \frac{\mu_{o}}{\sigma} \cdot N_{j} \cdot n_{j} \cdot k_{p j h} \cdot k_{d j h} \cdot i_{j} \cdot \frac{1}{h} \cdot \cos \left[h \cdot\left(\alpha-\alpha_{j}\right)\right]
$$

where $\mu_{o}$ is the air's magnetic permeability and $\sigma$ is the airgap's radial length.

In order to obtain the magnetic flux of phase " $\mathrm{j}$ " in phase "i", $\lambda_{\mathrm{ijh}}$, must be obtained the phase "j" magnetic flux who embraces phase "i". Therefore, starting from equation (8), can be obtained the mentioned magnetic flux and then the flux coupling between phases $\lambda_{\mathrm{ijh}}$, given by equation (9).

$$
\begin{aligned}
\lambda_{\mathrm{ijh}}=\mathrm{k}_{1} \cdot \mathrm{N}_{\mathrm{i}} \cdot \mathrm{N}_{\mathrm{j}} \cdot \mathrm{i}_{\mathrm{j}} \cdot \frac{\mathrm{k}_{\mathrm{wih}} \cdot \mathrm{k}_{\mathrm{wjh}}}{\mathrm{h}^{2}} \cos \left[\mathrm{h} \cdot\left(\alpha_{\mathrm{i}}-\alpha_{\mathrm{j}}\right)\right] \\
\mathrm{k}_{1}=4 \cdot \frac{2 \cdot \mathrm{p} \cdot \mathrm{L} \cdot \mathrm{R} \cdot \mathrm{n}_{\mathrm{i}} \cdot \mathrm{n}_{\mathrm{j}} \cdot \mu_{\mathrm{o}}}{\pi \cdot \sigma} \\
\mathrm{k}_{\mathrm{wih}}=\mathrm{k}_{\mathrm{pih}} \cdot \mathrm{k}_{\mathrm{dih}} \\
\mathrm{k}_{\mathrm{wjh}}=\mathrm{k}_{\mathrm{pjh}} \cdot \mathrm{k}_{\mathrm{djh}}
\end{aligned}
$$

where:

L - rotor cylinder length;

$\mathrm{R}$ - air-gap radial length;

$2 \mathrm{p}$ - machine pole number;

$\mathrm{n}_{\mathrm{i}}, \mathrm{n}_{\mathrm{j}}$ - coil number of phases " $\mathrm{i}$ " and " $\mathrm{j}$ ", respectively;

$\mathrm{N}_{\mathrm{i}}, \mathrm{N}_{\mathrm{j}}$ - turns number of phases " $\mathrm{i}$ ” and “ $\mathrm{j}$ ”, respectively;

$\mathrm{k}_{\mathrm{dih}}, \mathrm{k}_{\mathrm{djh}}$ - distribution factor of phases “i” $\mathrm{e}$ “ $\mathrm{j}$ ", respectively;

$\mathrm{k}_{\mathrm{pih}}, \mathrm{k}_{\mathrm{pjh}}$ - step factor of phases " $\mathrm{i}$ " e " $\mathrm{j}$ ", respectively.

It is important to mention that $\lambda_{\text {ijh }}$ doesn't include the phase mutual leakage flux.

The harmonic inductance of order $h$ between phases " $i$ " e "j", $\mathrm{L}_{\mathrm{ijh}}$, can be obtained through equation (13).

$$
L_{i j h}=\frac{\lambda_{i j h}}{i_{j}}
$$

Therefore, substituting (9) in (13) the following expression can be obtained:

$$
\begin{aligned}
& \mathrm{L}_{\mathrm{ijh}}=\mathrm{k}_{1} \cdot \mathrm{N}_{\mathrm{i}} \cdot \mathrm{N}_{\mathrm{j}} \cdot \frac{\mathrm{k}_{\mathrm{ijh}}}{\mathrm{h}^{2}} \cdot \cos \left[\mathrm{h}\left(\alpha_{\mathrm{i}}-\alpha_{\mathrm{j}}\right)\right] \\
& \mathrm{k}_{\mathrm{ijh}}=\mathrm{k}_{\text {wih }} \cdot \mathrm{k}_{\mathrm{wjh}}
\end{aligned}
$$

The total magnetic flux coupling of one phase, "i" as an example, $\lambda_{i}$, which can be split in the sum of contributions of magnetic flux coupling which embraces stator and rotor, $\lambda_{\mathrm{i}}{ }^{\prime}$, and the dispersion flux, $\lambda_{\mathrm{di}}$. Therefore, we have:

$$
\begin{aligned}
& \lambda_{\mathrm{i}}=\lambda_{\mathrm{di}}+\lambda_{\mathrm{i}}{ }^{\prime} \\
& \lambda_{\mathrm{di}}=\mathrm{L}_{\mathrm{i}} \cdot \mathrm{i}_{\mathrm{i}}
\end{aligned}
$$

where:

$\mathrm{L}_{\mathrm{i}}$ - dispersion inductance of phase "i".

The dispersion inductance can be supposed constant and therefore can be written: 
where:

$$
\mathrm{L}_{\mathrm{i}}=\mathrm{k}_{\mathrm{di}} \cdot \mathrm{N}_{\mathrm{i}}^{2}
$$

$\mathrm{k}_{\mathrm{di}}$ - magnetic circuit dispersion permeance.

Accordingly with reference [11], the flux coupling $\lambda_{i}$ ' can be obtained through the superposition of coupling harmonic components of all phases $\lambda_{\mathrm{ijh}}$. Therefore, can be written:

$$
\lambda_{\mathrm{i}}{ }^{\prime}=\sum_{\mathrm{j}} \sum_{\mathrm{h}} \lambda_{\mathrm{ijh}}
$$

From equations (13) and (19) we have:

$$
\lambda_{\mathrm{i}}{ }^{\prime}=\sum_{\mathrm{j}} \sum_{\mathrm{h}} \mathrm{L}_{\mathrm{ijh}} \cdot \mathrm{i}_{\mathrm{j}}
$$

from equations (16), (17) and (20) we obtain equation (21):

$$
\lambda_{\mathrm{i}}=\mathrm{L}_{\mathrm{i}} \cdot \mathrm{i}_{\mathrm{i}}+\sum_{\mathrm{h}} \sum_{\mathrm{j}} \mathrm{L}_{\mathrm{ijh}} \cdot \mathrm{i}_{\mathrm{j}}
$$

Finally, substituting equation (21) in equation (1) can be obtained the full voltage equation $\mathrm{v}_{\mathrm{i}}=\mathrm{r}_{\mathrm{i}} \cdot \mathrm{i}_{\mathrm{i}}+\mathrm{L}_{\mathrm{i}} \cdot \frac{\mathrm{di}_{\mathrm{i}}}{\mathrm{dt}}+\sum_{\mathrm{h}} \sum_{\mathrm{j}}\left[\mathrm{L}_{\mathrm{ijh}} \cdot \frac{\mathrm{di}_{\mathrm{j}}}{\mathrm{dt}}+\mathrm{i}_{\mathrm{j}} \cdot \frac{\mathrm{dL}_{\mathrm{ijh}}}{\mathrm{dt}}\right]$

Once defined the magnetic flux coupling general equation and voltage equation, those can be extended to the asymmetrical three-phase machine. In the matrix form we have:

$$
[\lambda]=[\mathrm{L}] .[\mathrm{I}]
$$

where:

$$
[\lambda]=\left[\begin{array}{c}
\lambda_{\mathrm{a}} \\
\lambda_{\mathrm{b}} \\
\lambda_{\mathrm{c}} \\
\lambda^{\prime}{ }_{\mathrm{A}} \\
\lambda_{{ }_{\mathrm{B}}}^{\prime} \\
\lambda_{\mathrm{C}}^{\prime}
\end{array}\right] \quad \text { (24) } \quad[\mathrm{I}]=\left[\begin{array}{c}
\mathrm{I}_{\mathrm{a}} \\
\mathrm{I}_{\mathrm{b}} \\
\mathrm{I}_{\mathrm{c}} \\
\mathrm{I}_{\mathrm{A}} \\
\mathrm{I}_{\mathrm{B}} \\
\mathrm{I}_{\mathrm{C}}^{\prime}
\end{array}\right]
$$

$$
[L]=k \cdot\left[\begin{array}{cccccc}
L_{11} & L_{12} & L_{13} & L_{14} & L_{15} & L_{16} \\
L_{12} & L_{22} & L_{23} & L_{24} & L_{25} & L_{26} \\
L_{13} & L_{23} & L_{33} & L_{34} & L_{35} & L_{36} \\
L_{14} & L_{24} & L_{34} & L_{44} & 0 & 0 \\
L_{15} & L_{25} & L_{35} & 0 & L_{44} & 0 \\
L_{16} & L_{26} & L_{36} & 0 & 0 & L_{44}
\end{array}\right]
$$

onde:

$$
\begin{aligned}
& \mathrm{L}_{11}=\sum_{\mathrm{h}} \frac{\mathrm{k}_{\text {aah }}}{\mathrm{h}^{2}}+\mathrm{K}_{\mathrm{L}}, \mathrm{L}_{22}=\sum_{\mathrm{h}} \frac{\mathrm{k}_{\mathrm{bbh}}}{\mathrm{h}^{2}}+\mathrm{K}_{\mathrm{L}}, \\
& \mathrm{L}_{33}=\sum_{\mathrm{h}} \frac{\mathrm{k}_{\mathrm{cch}}}{\mathrm{h}^{2}}+\mathrm{K}_{\mathrm{L}}, \quad L_{44}=\sum_{h} \frac{k_{R R h}}{h^{2}}\left[1-\cos \left(\frac{2 \pi}{3}\right)\right]+K_{L}^{\prime},
\end{aligned}
$$

$$
\begin{aligned}
& \mathrm{L}_{12}=\frac{1}{\mathrm{~b}} \cdot \sum_{\mathrm{h}} \frac{\mathrm{k}_{\mathrm{abh}}}{\mathrm{h}^{2}} \cdot \cos \left(\mathrm{h} \cdot \frac{2 \pi}{3}\right), \quad \mathrm{L}_{13}=\frac{1}{\mathrm{c}} \cdot \sum_{\mathrm{h}} \frac{\mathrm{k}_{\mathrm{ach}}}{\mathrm{h}^{2}} \cdot \cos \left(\mathrm{h} \cdot \frac{2 \pi}{3}\right), \\
& \mathrm{L}_{14}=\sum_{\mathrm{h}} \frac{\mathrm{k}_{\mathrm{aRh}}}{\mathrm{h}^{2}} \cdot \cos (\mathrm{h} \cdot \theta), \quad \mathrm{L}_{15}=\sum_{\mathrm{h}} \frac{\mathrm{k}_{\mathrm{aRh}}}{\mathrm{h}^{2}} \cdot \cos \left[\mathrm{h}\left(\theta+\frac{2 \pi}{3}\right)\right], \\
& \mathrm{L}_{16}=\sum_{\mathrm{h}} \frac{\mathrm{k}_{\mathrm{aRh}}}{\mathrm{h}^{2}} \cdot \cos \left[\mathrm{h}\left(\theta-\frac{2 \pi}{3}\right)\right], \mathrm{L}_{23}=\frac{1}{\mathrm{~b} \cdot \mathrm{c}} \cdot \sum_{\mathrm{h}} \frac{\mathrm{k}_{\mathrm{bch}}}{\mathrm{h}^{2}} \cdot \cos \left(\mathrm{h} \cdot \frac{2 \pi}{3}\right), \\
& \mathrm{L}_{26}=\frac{1}{\mathrm{~b}} \cdot \sum_{\mathrm{h}} \frac{\mathrm{k}_{\mathrm{h} \mathrm{bRh}}}{\mathrm{h}^{2}} \cdot \cos \left[\mathrm{h}\left(\theta-\frac{2 \pi}{3}\right)\right], \mathrm{L}_{25}=\frac{1}{\mathrm{~b}} \cdot \sum_{\mathrm{h}} \frac{\mathrm{k}_{\mathrm{bRh}}}{\mathrm{h}^{2}} \cdot \cos \left(\mathrm{h}\left(\theta+\frac{2 \pi}{3}\right)\right], \quad \mathrm{L}_{34}=\frac{1}{\mathrm{c}} \cdot \sum_{\mathrm{h}} \frac{\mathrm{k}_{\mathrm{cRh}}}{\mathrm{h}^{2}} \cdot \cos \left[\mathrm{h}\left(\theta+\frac{2 \pi}{3}\right)\right], \\
& \mathrm{L}_{35}=\frac{1}{\mathrm{c}} \cdot \sum_{\mathrm{h}} \frac{\mathrm{k}_{\mathrm{cRh}}}{\mathrm{h}^{2}} \cdot \cos \left[\mathrm{h}\left(\theta-\frac{2 \pi}{3}\right)\right], \quad \mathrm{L}_{36}=\frac{1}{\mathrm{c}} \cdot \sum_{\mathrm{h}} \frac{\mathrm{k}_{\mathrm{cRh}}}{\mathrm{h}^{2}} \cdot \cos (\mathrm{h} \cdot \theta), \\
& \quad b=\frac{N_{b}}{N_{a}}, \quad c=\frac{N_{c}}{N_{a}} \cdot
\end{aligned}
$$

where:

$\mathrm{k}$ - machine's magnetic circuit constant;

$\mathrm{Na}, \mathrm{Nb}, \mathrm{Nc}$ - turns number for phases " $\mathrm{a}, \mathrm{b}$ and c" of machine's stator, respectively.

For the three-phase asymmetrical machine with singlephase feeding, can be observed the presence of an additional capacitor between terminals "B" and "C", with the task to solve the machine's starting problem, and improve the performance in nominal steady-state conditions, as can be seen in Figure 3.



Figure 3 - Schematic diagram for the three-phase asymmetrical induction machine stator with single-phase feeding.

Through a complete analysis of electrical and mechanical equations for the asymmetrical machine, based on well established equations for a generic three-phase induction machine, we have:

$$
\begin{aligned}
& \mathrm{v}_{\mathrm{a}}=\mathrm{r}_{\mathrm{a}} \cdot \mathrm{i}_{\mathrm{a}}+\frac{\mathrm{d} \lambda_{\mathrm{a}}}{\mathrm{dt}} \\
& \mathrm{v}_{\mathrm{b}}=\mathrm{r}_{\mathrm{b}} \cdot \mathrm{i}_{\mathrm{b}}+\frac{\mathrm{d} \lambda_{\mathrm{b}}}{\mathrm{dt}} \\
& \mathrm{v}_{\mathrm{c}}=\mathrm{r}_{\mathrm{c}} \cdot \mathrm{i}_{\mathrm{c}}+\frac{\mathrm{d} \lambda_{\mathrm{c}}}{\mathrm{dt}}
\end{aligned}
$$

With Figure 3 as our reference, the following can be written:

$$
\begin{aligned}
& \mathrm{v}=\mathrm{v}_{\mathrm{a}}-\mathrm{v}_{\mathrm{c}} \\
& \mathrm{v}_{\text {Cap }}=\mathrm{v}_{\mathrm{b}}-\mathrm{v}_{\mathrm{c}} \\
& \mathrm{i}_{\text {Cap }}=\operatorname{Cap} \cdot \frac{\mathrm{dv} \mathrm{v}_{\text {Cap }}}{\mathrm{dt}}=-\mathrm{i}_{\mathrm{b}}
\end{aligned}
$$




$$
i_{c}=-\left(i_{a}+i_{b}\right)
$$

Mathematical manipulation of equations from (27) to (33), give us:

$$
\begin{aligned}
& \mathrm{v}=\left(\mathrm{r}_{\mathrm{a}}+\mathrm{r}_{\mathrm{c}}\right) \cdot \mathrm{i}_{\mathrm{a}}+\mathrm{r}_{\mathrm{c}} \cdot \mathrm{i}_{\mathrm{b}}+\frac{\mathrm{d} \lambda_{\mathrm{ac}}}{\mathrm{dt}} \\
& \mathrm{v}_{\text {Cap }}=\left(\mathrm{r}_{\mathrm{b}}+\mathrm{r}_{\mathrm{c}}\right) \cdot \mathrm{i}_{\mathrm{b}}+\mathrm{r}_{\mathrm{c}} \cdot \mathrm{i}_{\mathrm{a}}+\frac{\mathrm{d} \lambda_{\mathrm{bc}}}{\mathrm{dt}}
\end{aligned}
$$

where:

$$
\begin{aligned}
& \lambda_{\mathrm{ac}}=\lambda_{\mathrm{a}}-\lambda_{\mathrm{c}} \\
& \lambda_{\mathrm{bc}}=\lambda_{\mathrm{b}}-\lambda_{\mathrm{c}}
\end{aligned}
$$

For the short-circuited rotor we have:

$$
\begin{aligned}
& 0=\mathrm{r}_{\mathrm{R}}^{\prime} \cdot \mathrm{i}_{\mathrm{A}}+\frac{\mathrm{d} \lambda_{\mathrm{A}}}{\mathrm{dt}} \\
& 0=\mathrm{r}_{\mathrm{R}}^{\prime} \cdot \mathrm{i}_{\mathrm{B}}^{\prime}+\frac{\mathrm{d} \lambda^{\prime}{ }_{\mathrm{B}}}{\mathrm{dt}} \\
& 0=\mathrm{r}_{\mathrm{R}}^{\prime} \cdot \mathrm{i}_{\mathrm{C}}^{\prime}+\frac{\mathrm{d} \lambda_{\mathrm{C}}^{\prime}}{\mathrm{dt}}
\end{aligned}
$$

In order to solve the system of equations from (34) to (38) it is necessary to relate the magnetic flux coupling with stator and rotor currents. For an asymmetrical machine, the following can be written:

$$
\left[\begin{array}{c}
\lambda_{\mathrm{a}} \\
\lambda_{\mathrm{b}} \\
\lambda_{\mathrm{c}} \\
\lambda_{\mathrm{A}}{ }^{\prime} \\
\lambda_{\mathrm{B}}{ }^{\prime} \\
\lambda_{\mathrm{C}}{ }^{\prime}
\end{array}\right]=[\mathrm{L}] \cdot\left[\begin{array}{c}
\mathrm{i}_{\mathrm{a}} \\
\mathrm{i}_{\mathrm{b}} \\
\mathrm{i}_{\mathrm{c}} \\
\mathrm{i}_{\mathrm{A}}{ }^{\prime} \\
\mathrm{i}_{\mathrm{B}}{ }^{\prime} \\
\mathrm{i}_{\mathrm{C}}{ }^{\prime}
\end{array}\right]
$$

where $[\mathrm{L}]$ is the inductance matrix from equation 26. (40).

From equations (33) and (39) can be obtained equation

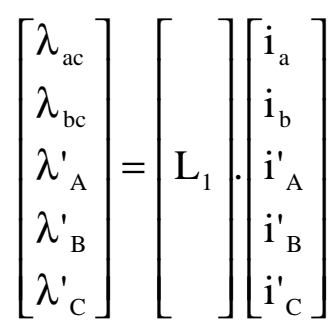

where:

$$
\left[L_{1}\right]=k \cdot\left[\begin{array}{ccccc}
A_{11} & A_{12} & A_{13} & A_{14} & A_{15} \\
A_{12} & A_{22} & A_{23} & A_{24} & A_{25} \\
A_{13} & A_{23} & A_{33} & 0 & 0 \\
A_{14} & A_{24} & 0 & A_{33} & 0 \\
A_{15} & A_{25} & 0 & 0 & A_{33}
\end{array}\right]
$$

The terms in matrix $\left[\mathrm{L}_{1}\right]$ are:

$\mathrm{A}_{11}=\mathrm{L}_{11}-2 . \mathrm{L}_{13}+\mathrm{L}_{33} ; \mathrm{A}_{12}=\mathrm{L}_{12}-\mathrm{L}_{23}-\mathrm{L}_{13}+\mathrm{L}_{33}$;
$\mathrm{A}_{13}=\mathrm{L}_{14}-\mathrm{L}_{34} ; \mathrm{A}_{14}=\mathrm{L}_{15}-\mathrm{L}_{35} ; \mathrm{A}_{15}=\mathrm{L}_{16}-\mathrm{L}_{36} ;$

$\mathrm{A}_{22}=\mathrm{L}_{22}-2 . \mathrm{L}_{23}+\mathrm{L}_{33} ; \mathrm{A}_{23}=\mathrm{L}_{24}-\mathrm{L}_{34}$;

$\mathrm{A}_{24}=\mathrm{L}_{25}-\mathrm{L}_{35} ; \mathrm{A}_{25}=\mathrm{L}_{26}-\mathrm{L}_{36} ; \mathrm{A}_{33}=\mathrm{L}_{44}$.

Where the values of $\mathrm{L}_{\mathrm{ij}}$ are the terms of the matrix in equation (26).

The machine's mechanical equations are introduced as in the following equations:

$$
\begin{aligned}
& T m-T c=J \cdot \frac{d w_{R}}{d t} \\
& w_{R}=\frac{d \theta_{R}}{d t}
\end{aligned}
$$

where:

$\mathrm{J}$ - inertia moment of rotating parts; $\mathrm{w}_{\mathrm{R}}$ - machine's angular speed;

degrees;

$$
\theta_{R} \text { - angular displacement, in mechanical }
$$

$\mathrm{Tm}$ - electromagnetic torque;

Tc - load torque.

The electromagnetic torque is given by:

$T m=\frac{p}{4} \cdot\left[\begin{array}{llllll}i_{a} & i_{b} & i_{c} & i_{A}^{\prime} & i_{B}^{\prime} & i_{C}{ }_{C}\end{array}\right]\left[\frac{d[L]}{d \theta}\right]\left[\begin{array}{c}i_{a} \\ i_{b} \\ i_{c} \\ i_{A}{ }_{A} \\ i_{B}{ }_{B} \\ i_{C}{ }_{C}\end{array}\right]$

where:

$$
\begin{aligned}
& \mathrm{p} \text { - pole number; } \\
& {[\mathrm{L}] \text { - inductance matrix in equation (26); }} \\
& \theta \text { - angular displacement in electrical degrees. }
\end{aligned}
$$

In order to obtain a system of equations which represents the functional behavior of an asymmetrical induction machine with single phase feeding, it is enough to mix the electrical equations from (34) to (39) with the mechanical equations from (42) to (44).

\section{HOW TO DESIGN AND BUILD A PROTOTYPE}

The design of a three-phase asymmetrical is made from an ordinary three-phase symmetrical induction motor, the only difference are the changes made in the original windings with the stator and squirrel cage rotor magnetic structure being preserved. Initially, a 2 HP, 4 poles, $220 / 380 \mathrm{~V}$, ordinary commercial three-phase induction motor was tested in the laboratory in order to obtain its equivalent circuit parameters, as given in Table 1, in this motor the equivalent circuit is the same for each phase. With the parameters and the motor model, a number of results were obtained for phase turns number and capacitance $\mathrm{C}_{\mathrm{ap}}$, for each case torque oscillations were measured, and the result which showed lower oscillation, at nominal condition for torque and speed was:

$$
\mathrm{Nb}=0.60 \mathrm{Na} ; \mathrm{Nc}=1.40 \mathrm{Na} ; \mathrm{Cap}=40 \mu \mathrm{F}
$$

\section{Digital SIMULATION}

With the machine's equivalent circuit data, the turns number relationships and the capacitance value, theoretical 
simulation results can be obtained considering the machine's spatial harmonics or only the fundamental (first harmonic), as can be seen in Figures 4, 5, 6 and 7.

Table 1. Equivalent circuit parameters for the three-phase induction machine.

\begin{tabular}{|c|c|}
\hline \multicolumn{2}{|c|}{$\begin{array}{c}\text { Stator and Rotor Phase Data da defesa } \\
\text { (referred to the stator) }\end{array}$} \\
\hline Stator Resistance & $3,80 \pm 0,03 \Omega$ \\
\hline Rotor Resistance & $3,01 \pm 0,03 \Omega$ \\
\hline Blocked Rotor Reactance & $3,10 \pm 0,03 \Omega$ \\
\hline Magnetization Reactance & $75,15 \pm 0,7 \Omega$ \\
\hline
\end{tabular}

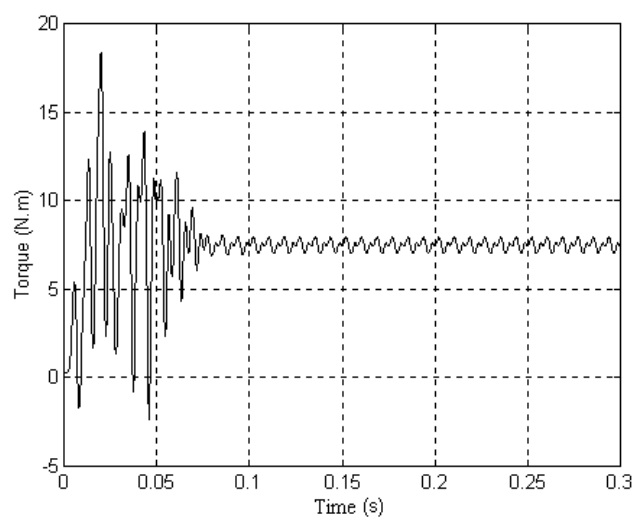

Figure 4 - Asymmetrical three-phase induction motor torque with singlephase feeding. - First harmonic only.

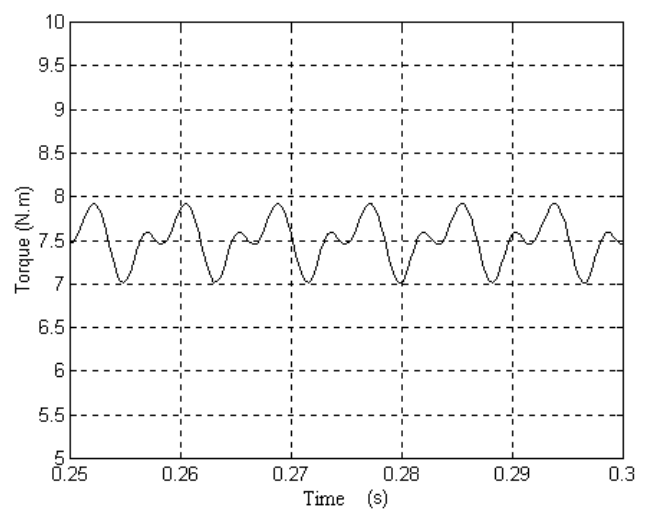

Figure 5 - Asymmetrical three-phase induction motor torque with singlephase feeding. - First harmonic only.

Through figures 4, 5, 6 and 7, can be observed that the asymmetrical three-phase induction motor torque with single-phase feeding shows satisfactory torque oscillations under nominal load conditions. Can be also observed that the inclusion of machine's spatial harmonics doesn't change much its behavior concerning torque oscillations.

\section{EXPERIMENTAL RESULTS}

Since confirmed the asymmetrical three-phase induction motor good behavior with single phase feeding, a prototype was built and tested under load conditions, the objective was to validate the theoretical results using the laboratory experimental results as the real case. Therefore, the test bench in the lab was assembled as shown in Figure 8.

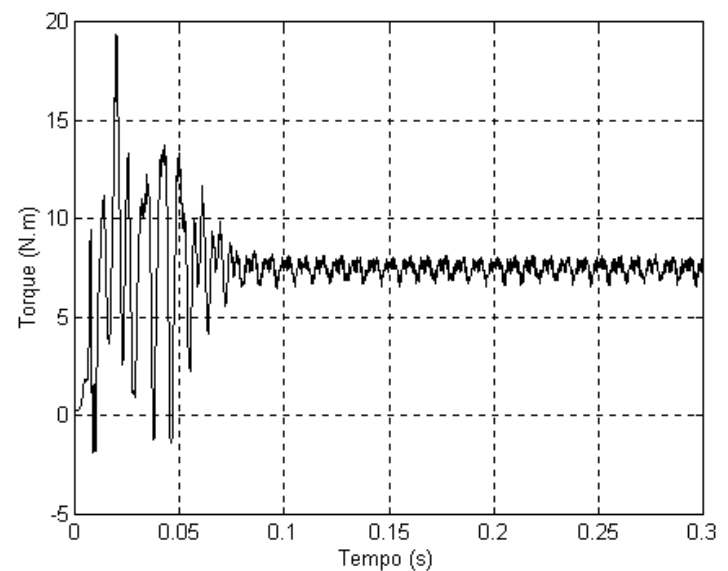

Figure 6 - Asymmetrical three-phase induction motor torque with singlephase feeding. - Up to the $30^{\text {th }}$ harmonic.

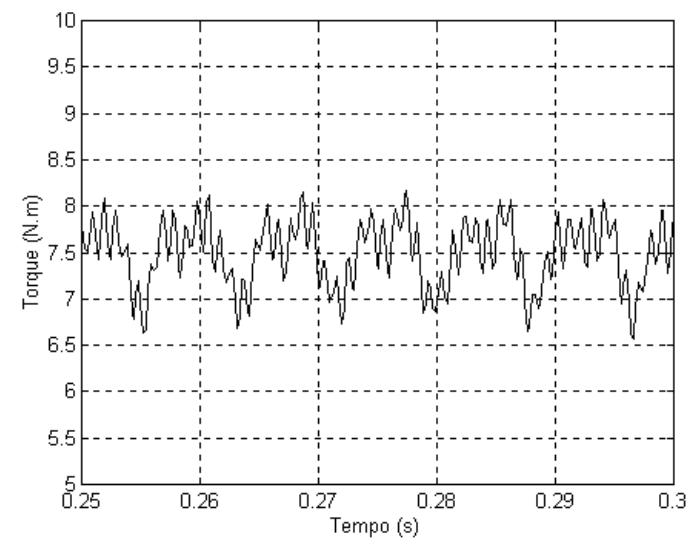

Figure 7 - Asymmetrical three-phase induction motor torque with singlephase feeding. - Up to the $30^{\text {th }}$ harmonic.

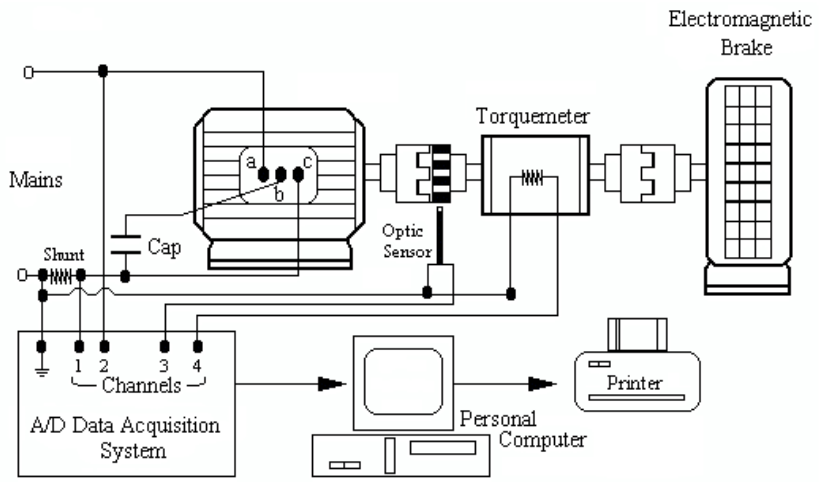

Figure 8 - Bench test assembled in order to measure the variables for the asymmetrical three-phase induction motor.

Figure 9 shows the asymmetrical three-phase induction motor torque with single phase feeding in steady-state under nominal load conditions.

\section{SYMMETRICAL AND ASYMMETRICAL MOTORS - COMPARISON}

As a verification only, to check the torque oscillations presented by the asymmetrical three-phase induction motor, analysis is made for the same power symmetrical three-phase induction motor, fed by a three-phase voltage 
system with a perfectly acceptable voltage unbalance in electrical systems of around $2 \%$ between phases.

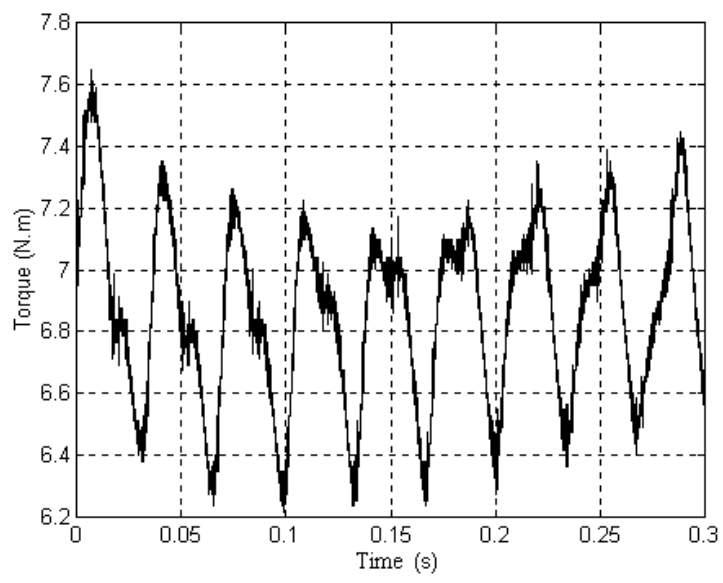

Figure 9 - Asymmetrical three-phase induction motor torque at nominal conditions with single-phase feeding.

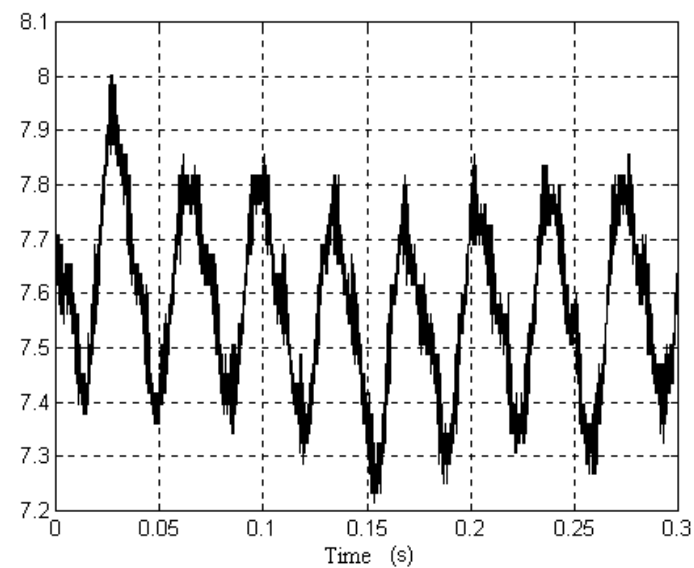

Figure 10 - Symmetrical three-phase induction motor torque at nominal conditions.

\section{CONCLUSIONS}

From the analysis of Figures 4, 5, 6, 7 and 8 can be observed that results obtained from simulations match almost perfectly to the results obtained from experimental tests, and the model used is perfectly validated. Comparing Figures 9 and 10, can also be observed that even with the asymmetrical induction motor submitted to a normal voltage unbalance from the source, torque oscillations, produced by this unbalance, are close to the torque oscillations presented in the symmetrical three-phase induction motor from normal voltage unbalance in the source. Therefore, it is demonstrated that the validation of the model presented, and also the satisfactory performance of the asymmetrical three-phase induction motor under single-phase feeding.

\section{VIII - BIOGRAPHY}

Roberlam G. de Mendonça - Mr. Mendonça was born in Itabuna, Bahia, Brazil in May $6^{\text {th }}, 1969$. He did his BSc in Electrical and Electronic Engineering from UNIVALE - Universidade do Vale do Rio Doce, Governador Valadares, MG, Brazil in 1991. Finished his MSc degree in Electrical Engineering in 1997 at UFU - Universidade Federal de Uberlândia, MG, Brazul. He is a lecturer from CEFET - Centro Federal de
Educação Tecnológica, Jataí , GO. Currently he is pursuing his Doctoral Degree in Electrical Engineering at UFU, his area of interest is Electrical Machines.

Luciano Martins Neto - Dr. Martins Neto was born in Botucatu, SP, Brazil on May 22 $2^{\text {nd }}, 1948$. He has a Doctoral degree in Mechanical Engineering from Escola de Engenharia de São Carlos at Universidade de São Paulo (USP), São Carlos, Brazil since 1980. Worked as a lecturer at Faculdade de Engenharia de Lins, Lins, SP, Brazil, at Escola de Engenharia de São Carlos ( USP), São Carlos, Brazil and at the Electrical Engineering Department (UNESP - Universidade Estadual Paulista) at Ilha Solteira, SP, Brazil. He is currently working as a Senior Lecturer at Universidade Federal de Uberlândia, MG, Brazil. His areas of interest are Electrical Machines and Grounding.

José Roberto Camacho - Dr. Camacho was born in Taquaritinga, SP, Brazil on November $3^{\text {rd }}$, 1954. Completed his PhD degree in the Electrical and Electronic Engineering Department at the University of Canterbury, Christchurch, New Zealand, in August 1993. He is a Senior Lecturer at Universidade Federal de Uberlândia where he works since February 1979. Dr. Camacho is a Researcher-Consultant of CNPq (Brazilian National Council for Scientific and Technological Development) and worked as a collaborator-member of Brazilian Committee of CIGRÉ-JWG 11/14-09 (Unit Connection). His areas of interest are Dynamic Simulation, Electrical Machines and HVAC-DC conversion.

\section{REFERENCES}

[1] - Richard, Jean-Claude, A Comparative Study Between Single-Phase and Asymmetrical Three-Phase Induction Motors, Master's Dissertation (in Portuguese), UFU - 1993.

[2] - Alvarenga, B.P., Model for the Computation of Torque for an Induction Machine Including Winding and Saturation Effects, Master's Dissertation (in Portuguese), UFU - 1993.

[3] - Chaves, M.L.R., Design and Assembling of Static Systems for Feeding Three-Phase Loads from Single-Phase Networks, Master's Dissertation (in Portuguese), UFU - 1987.

[4] - Martins Neto, L., Single-Phase Feeding of Asymmetrical ThreePhase Induction Motor, I Electrical Energy Distribution International Seminar, (in Portuguese), Belo Horizonte, MG, Brazil, October 1990.

[5] - Alwash, J.H.H. \& Ikhawan, S.H.; Generalised Approach to the Analysis of Asymmetrical Three-Phase Induction Motors, IEE Proc. Eletric. Power Appl., Vol 142 No. 2, March 1995.

[6] - Martins Neto, L., Mendonça, R.G., Camacho, J.R. \& Salerno, C.H. ; The Asymetrical Three-Phase Induction Motor Fed by Single Phase Source: Comparative Performance Analysis. IEEE - IEMDC, International Eletric Machines and Drives Conference. Milwaukee, Wisconsin, May 1997.

[7] - Martins Neto, L., Mendonça, R.G., Camacho, J.R. \& Andrade, D.A.; Asymmetrical Three-Phase Induction Motor Under Single Phase Feeding: Oscillating Torque, Theoretical and Experimental Analysis - Harmonic Effects, ICEM-98, International Conference on Electrical Machines. Turkey, Istanbul, September 1998.

[8] - Martins Neto, L., Mendonça, R.G., Camacho, J.R. \& Andrade, D.A. Single Phase and Asymmetrical Three-Phase Induction Motors: A Comparative Steady-State Analysis Under Single-Phase Feeding. ICEM98, International Conference on Electrical Machines. Turkey, Istanbul, September 1998.

[9] - Mendonça, R.G \& Martins Neto, L; Comparative Performance Analysis: Oscillating Torque of Symmetrical and Asymmetrical ThreePhase Induction Motors, (in Portuguese), Proceedings of XII Brazilian Automatic Control Conference - XII CBA, Vol. I, pp.243-247-September 1418, 1998 - Uberlândia, MG, Brazil.

[10] - Martins Neto, L., Salerno, C.H., Bispo, D. \& Alvarenga, B. P.; Induction Motor Torque: An Approach Including Windings And Saturation Effects, International Conference on Electrical Machines in Australia - ICEMA. Adelaide, University of South Australia , September 1993.

[11] - Martins Neto, L., Camacho, J.R., Salerno, C.H. \& Alvarenga, B.P.; Analysis of a Three-Phase Induction Machine Including Time and Space Harmonic Effects: The A, B, C Reference Frame; PES-IEEE Transactions on Energy Conversion, Volume 14, Nr. 1, March 1999. Article number: PE-154-EC-0-10-1997. 